\title{
قراءة في كتاب \\ "الشورى في معركة البناء" \\ تأليف: أحمد الريسوني فيركه
}

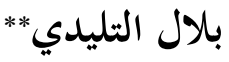

الكتاب الذي بين أيدينا، هو من نوع الإنتاج العلمي التي يتبناه المعهد العلمي للفكر

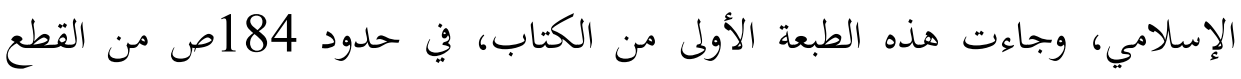

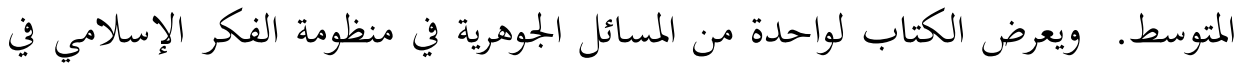

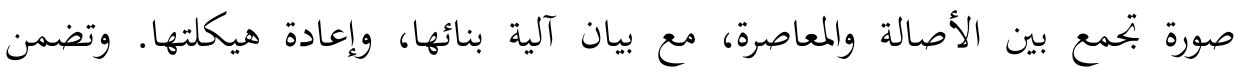

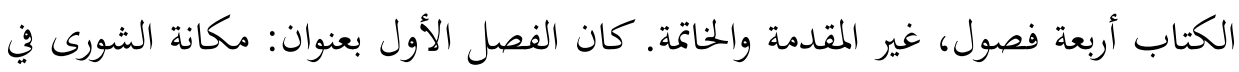

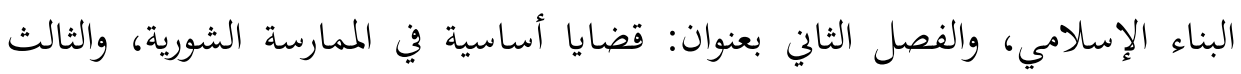

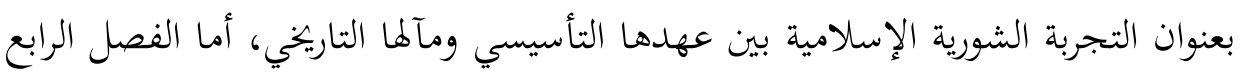

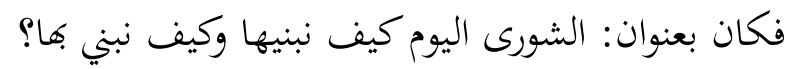

نستطيع القول إن موضوع الشورى ما زال يفرض راهنيته في البحث المعربف

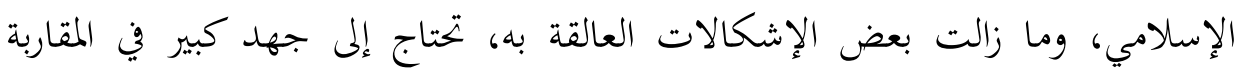

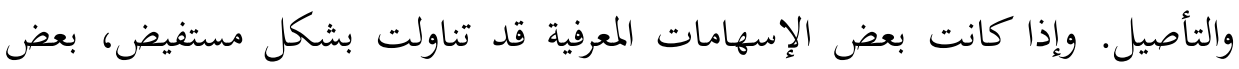

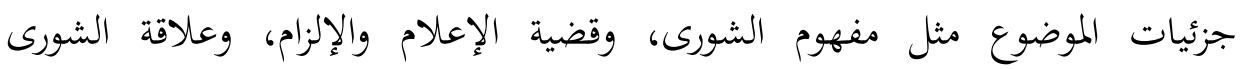

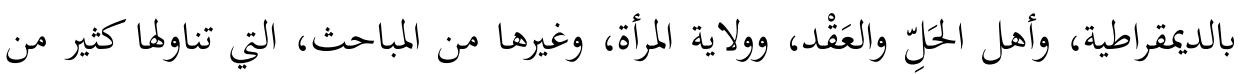

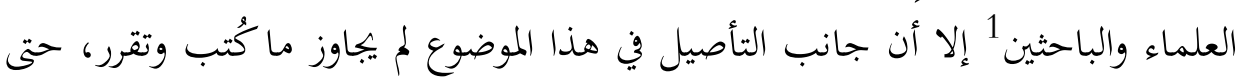

" الريسوني، أمد. الشورى في معركة البناء، 11، المعهد العلمي للفكر الإسلامي/مكتب الأردن، عمان: دار الرازي، 2007

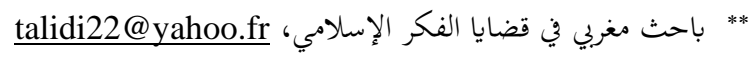
1 نشرت في السنوات الأخيرة كتب كثيرة عن نظام الشورى في الإسلام، وإمكانيات تطبيقها في الواقع المعاصر،

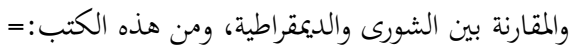


صار من المبسلَّم به لأي باحث متحدث في موضوع الشورى، أن يجعل آيتي الشورى

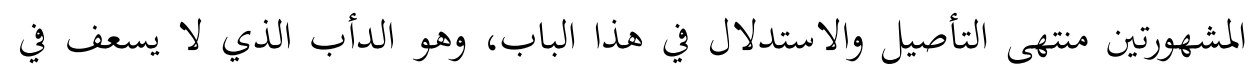

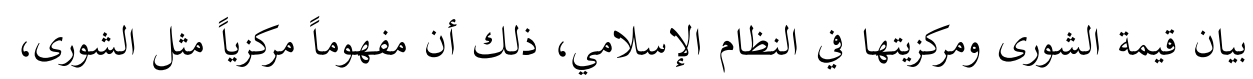

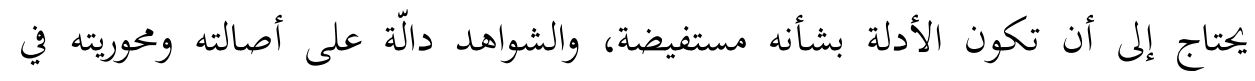
التصور الإسلامي. - إن.

إن أي مفهوم مركزي في التصور الإسلامي يمتاج إلى التأصيل والتقصيد، كما يمتاج

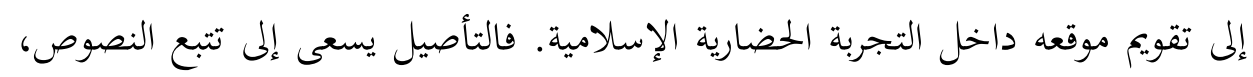

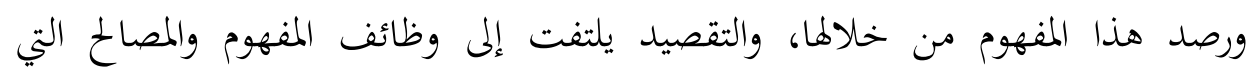

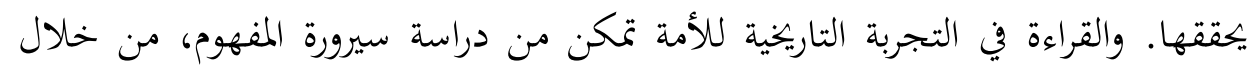
واقع ممارسته، كما تسمح بالنظر في عوائق التطبيق وأوجه الاختلال. غير أن الكتابات التي تناولت موضوع الشورى، لم تعط جانب التأصيل والتقصيد ما يستحقه من عناية، ولولا بعض الإشارات الدالة في كتاب الدكتور حسن الترابي حول "الشورى والديمقراطية"، حول محورية الشورى في كل مجالات الدين، بما في ذلك العبادة والصلاة، لظل موضوع الشورى حكراً على قضايا السياسة وتدبير الشأن العام. ولولا بعض النظرات النقدية التي

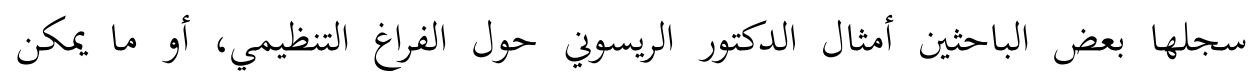

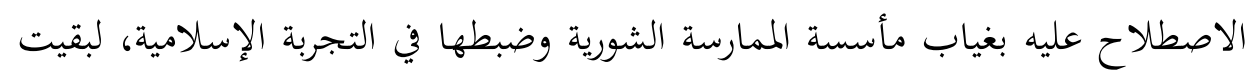

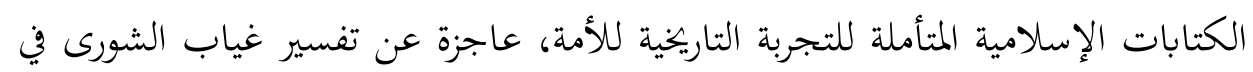
الممارسة السياسية للأمة.

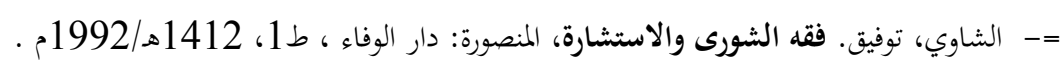

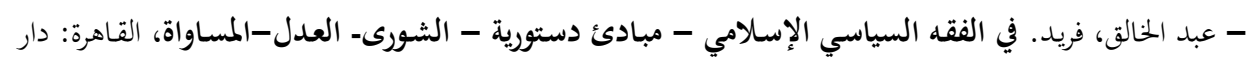
الشروق، 1998.

- فتوح، محمد عبد الفتاح. الديمقراطية والشوري في الفكر الاسلامي المعاصر دراسة في فكر الشيخ حممد الغزالي ، القاهرة: مكتبة الشروق الدولية، 2006. - إبراهيم، زكريا عبد المنعم. نظام الشورى في الاسلام ونظم الديمقطية المعاصرة ، القاهرة: مكتبة النهضة المصرية، 
وكتاب الريسوني "الشورى في معركة البناء"، حاول أن يسد ثغرة كبيرة في المكتبة

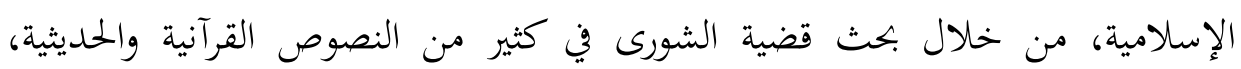

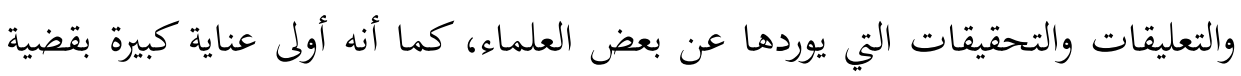

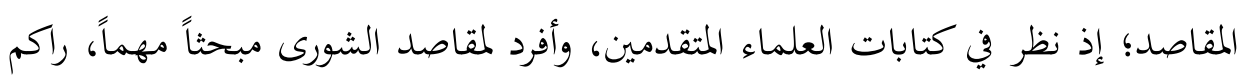

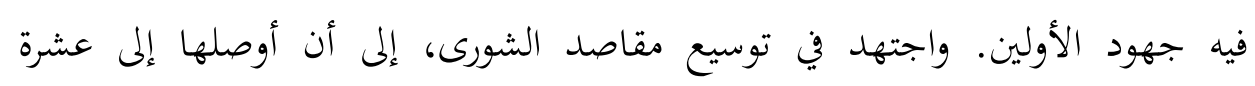

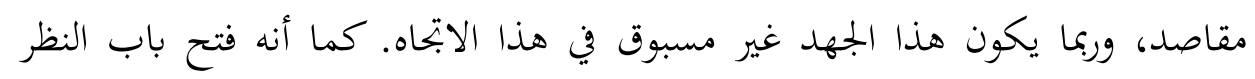

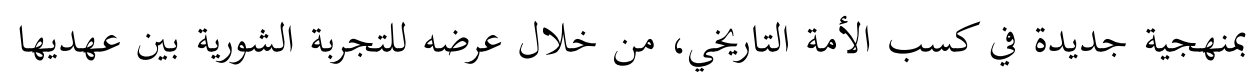
التأسيسي ومآلها التاريخي.

وهذا الكتاب، وإن لم يشر إلى كتابات من سبقه كما جرت عادة الباحثين، إلا أنه

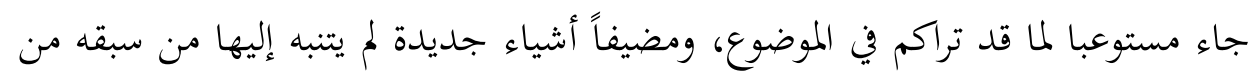

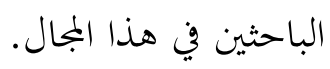

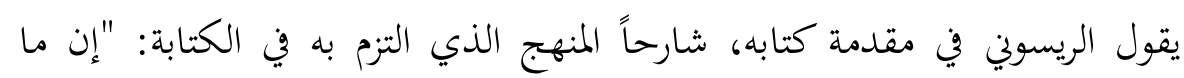

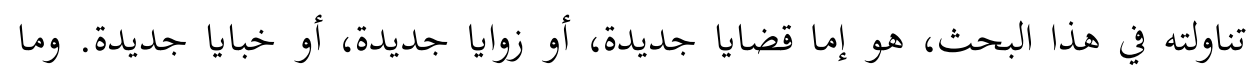

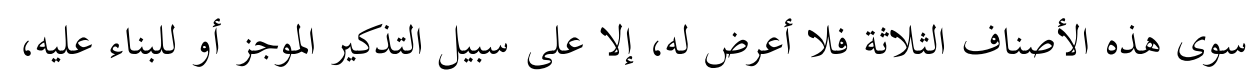

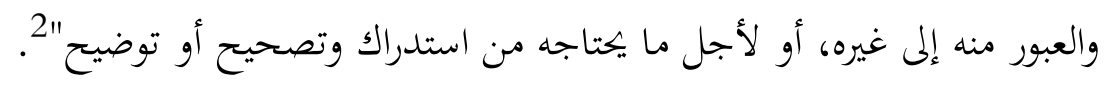

وتحاشى الريسوني الوقوف عند التعريفات اللغوية والاصطلاحية، وأعرض عن

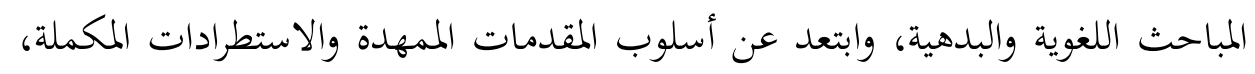

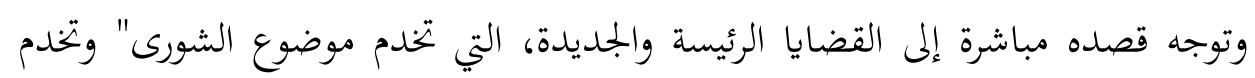

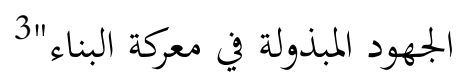

ولذلك، يمكن القول : إن ما يميز الكتاب عن سائر ما سبقه من جهود في هذا الموضوع، هو الحضور الكثيف للتأصيل. فقد غاص الريسوني في عدد من آنسات آيات القرآن

$$
\text { 32 } 23 .
$$


الكريم، واستقرأ وقائع كثيرة من السنة النبوية، ومن سنة الخلفاء الراشدين، وبدا الحشد الخداء

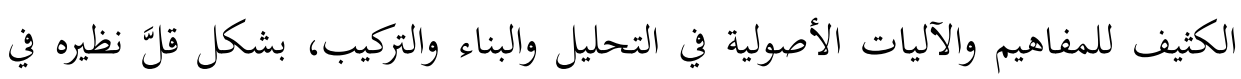

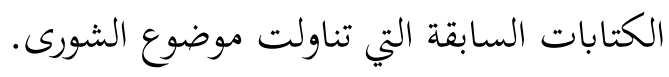

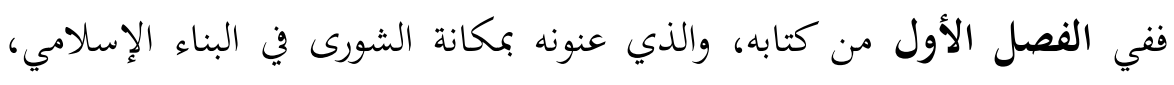

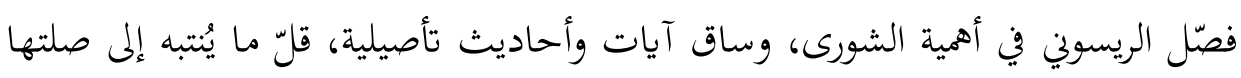

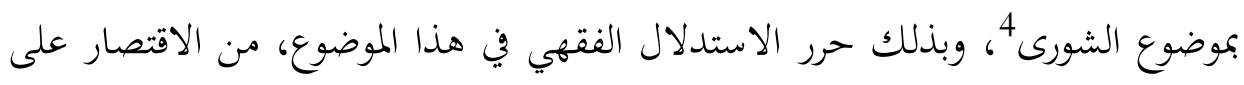

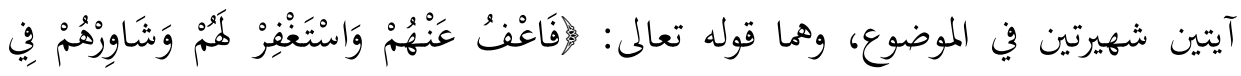

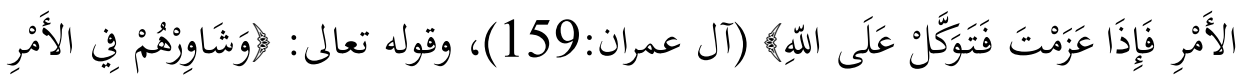

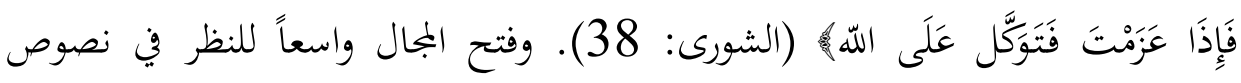

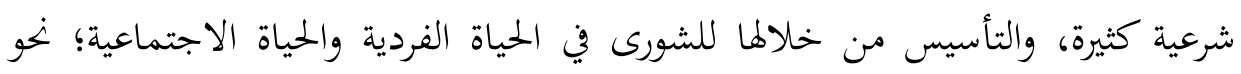

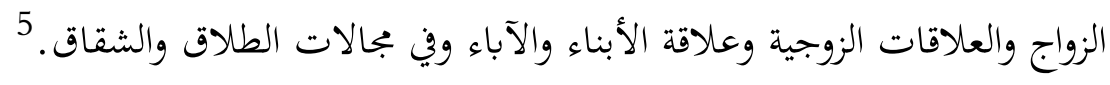

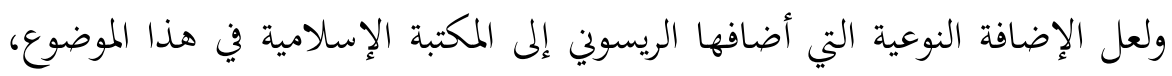

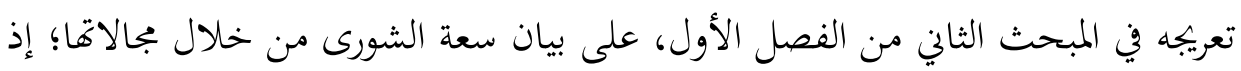

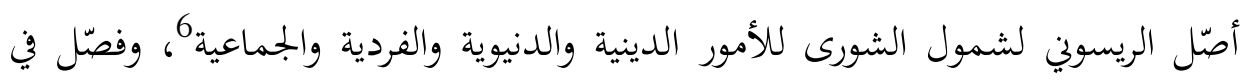

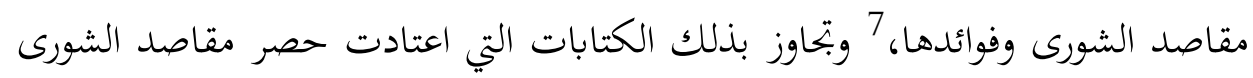

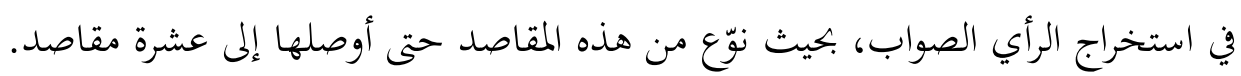

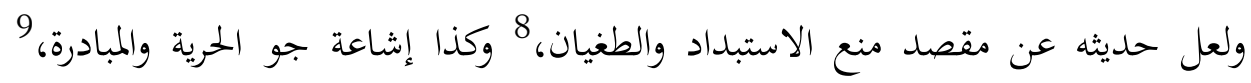
وتنمية القدرة على التفكير والتدبير، 10 يعد إضافة نوعية في هذا ولمنيان، وكذال المجال.

$$
\begin{aligned}
& 4 \text { المرجع السابق،ص15 وما بعدها. }
\end{aligned}
$$

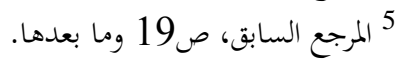

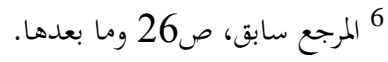

$$
\begin{aligned}
& 7 \text { المرجع السابق، ص35 صابق، صما صما بعدها. } \\
& 8 \text { المرجع السابق ص38. } \\
& 9 \text { المرجع السابق } 41 . \\
& 10 \text { المرجع السابق، ص44. }
\end{aligned}
$$


وبعد جهد التأصيل، وبيان أهمية الشورى وبجالاتا ومقاصدها، شرع الريسوني في

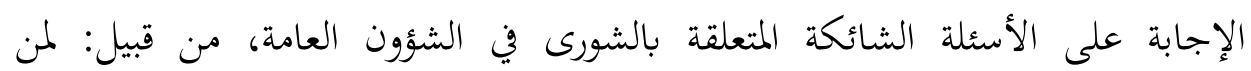

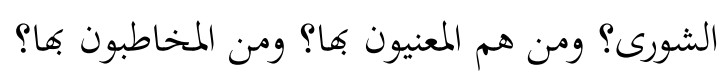

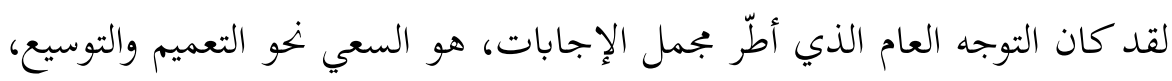

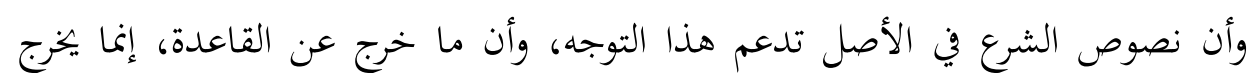

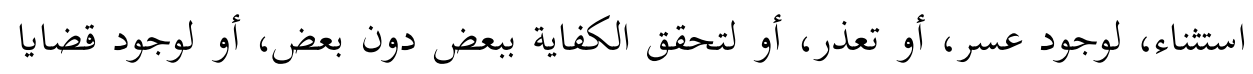

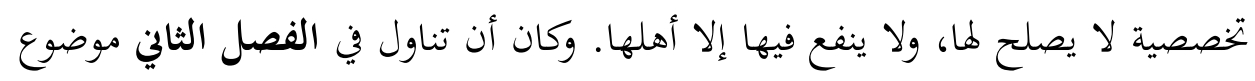

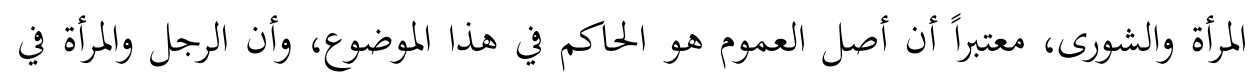

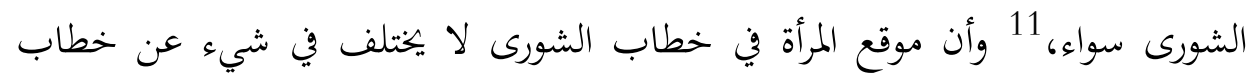

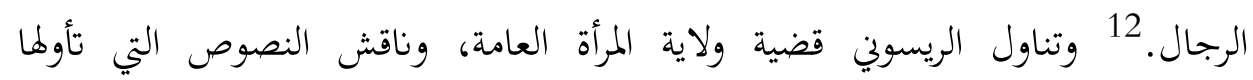

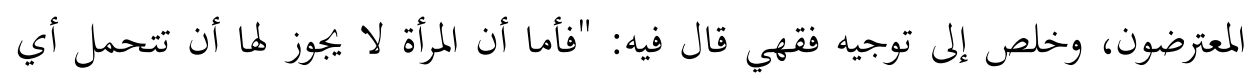

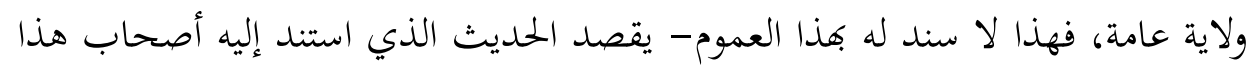
الرأي- وهذا الإطلاق."

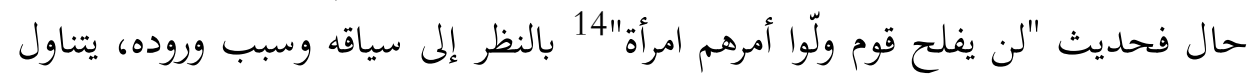

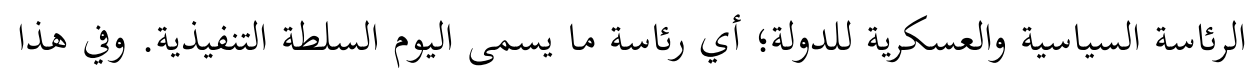

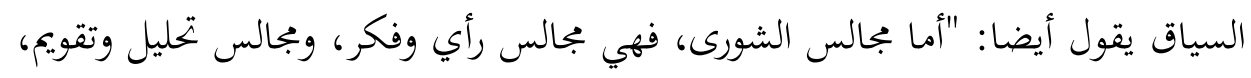

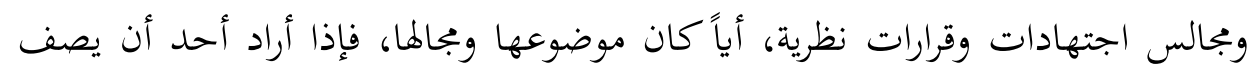

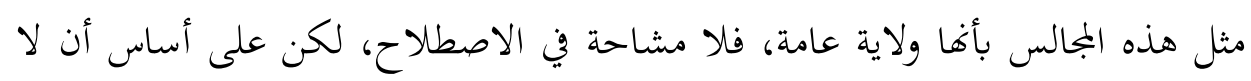

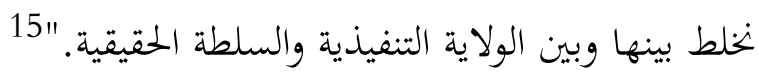

$$
12 \text { } 11 \text { المرجع السابق ص55. } 13 \text { المرجع السابق ص56. }
$$

14 البخاري، حمد بن إسماعيل. صحيح البخاري، دط، الرياض: بيت الأفكار الدولية للنشر والتوزيع، 1956،

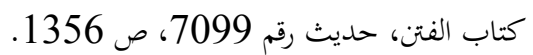

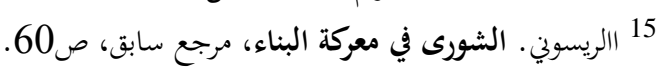


تم عرج الريسوين في المبحث الثاني من الفصل الثاني، على عضوية بجالس الشورى،

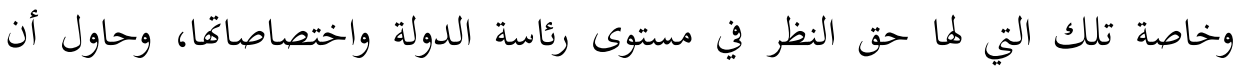

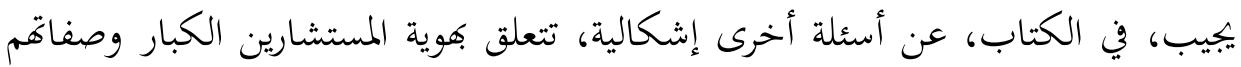
وطريقة اختيارهم.

وبعد تفصيله في الصفات التي تحدث عنها العلماء في الموضوع ومناقشتها، انتهى

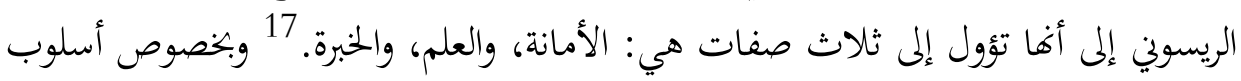
اختيار المستشارين الكبار، تحدث الريسوين عن طريقة الانتخاب وطريقة التعيين، ورأى ضرورة

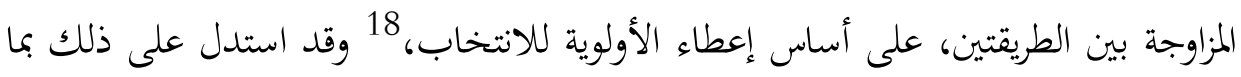
ثبت من أدلة الشرع، وبما استقر من أحكام العقل.

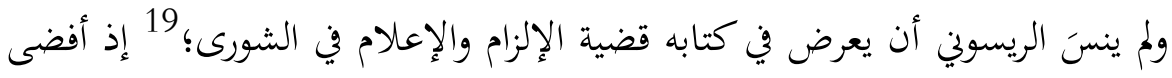

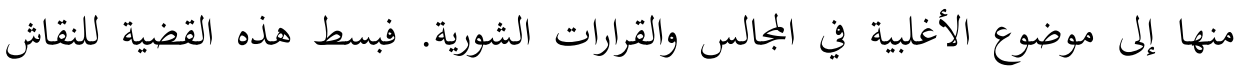

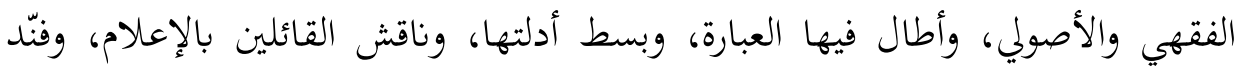

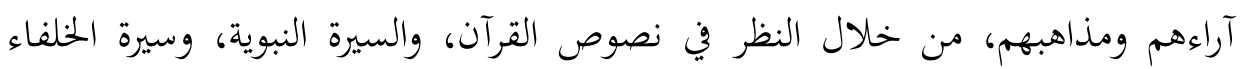
الراشدين، ومن خلال قواعد الفقهاء والأصوليين وعلماء الحديث.

وتناول الريسوني في الفصل الثالث من كتابه، التجربة الشورية بالتأمل والتقويم،

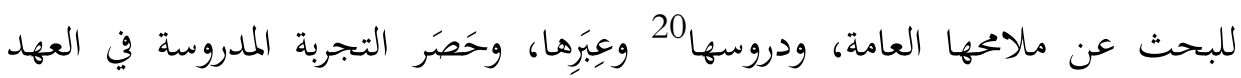
النبوي والخلافة الراشدة، وانتهى منها إلى استخلاص الخصائص الشورية ممثلةً ف: الحضور القوي والمؤثر للممارسة الشورية، والحرية الكاملة في التفكير والتعبير، والمبادرة، والصدق، والصراحة، والنزاهة، والثقة، والبساطة، والمرونة التنظيمية في ممارسة الشورى. 21

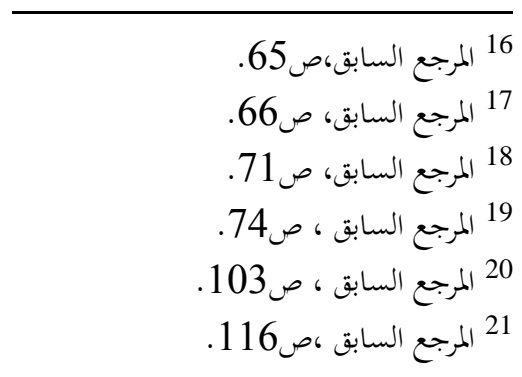




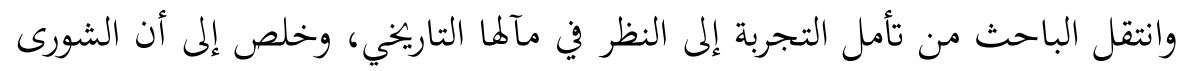

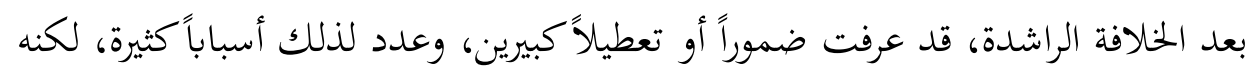

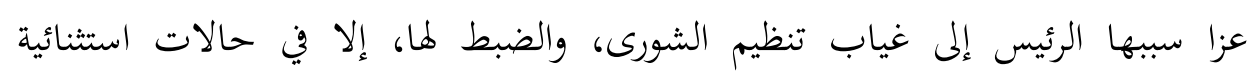

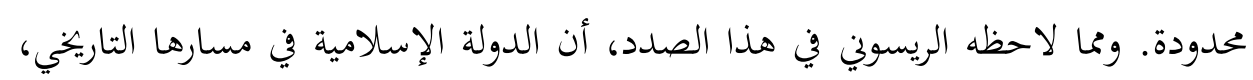

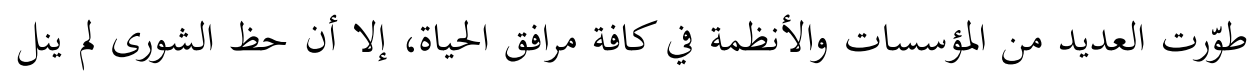

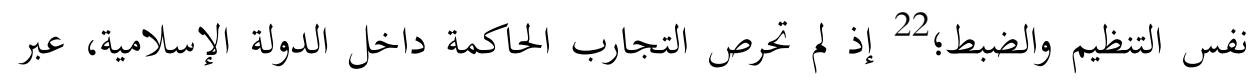

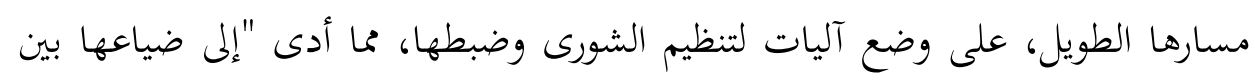

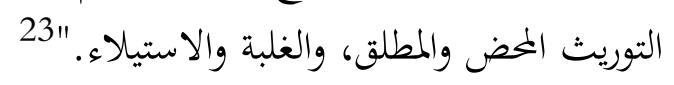

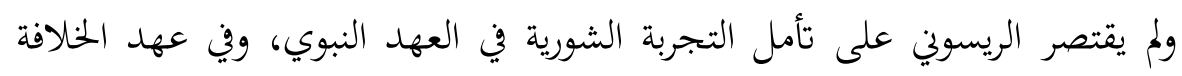

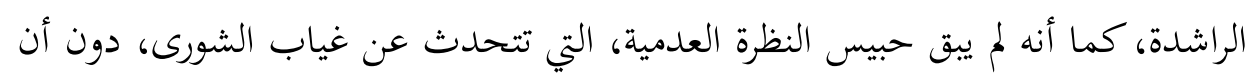

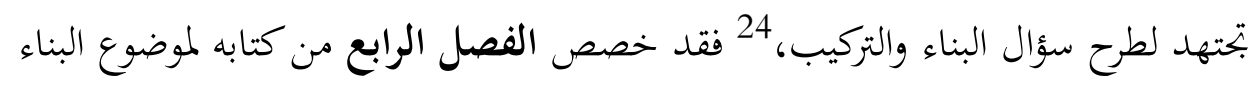

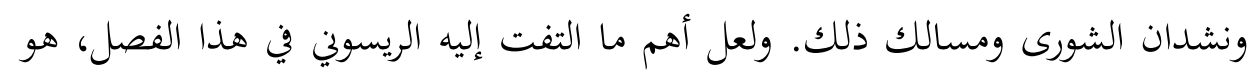

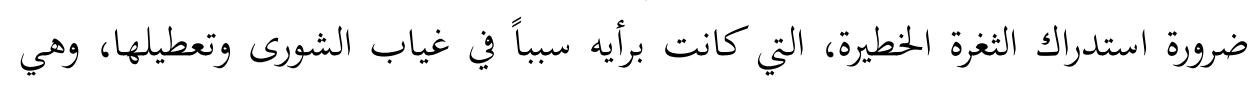

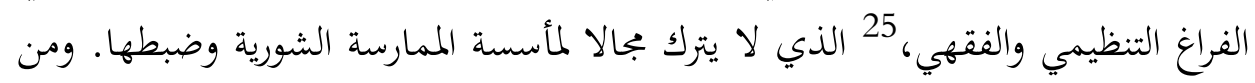

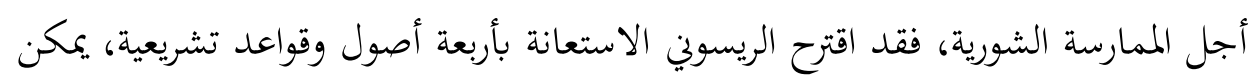

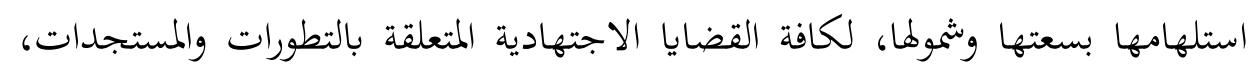

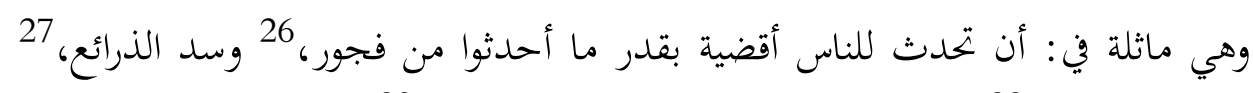

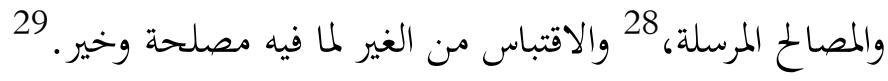

$$
\begin{aligned}
& 22 \text { المرجع السابق ، ص120. } \\
& 23 \text { المرجع السابق، صرابع، ص122. } \\
& 24 \text { المرجع السابق، صلمرجع، ص131. }
\end{aligned}
$$

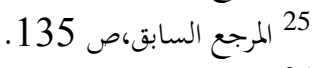

$$
\begin{aligned}
& 26 \text { المرجع السابق،صابع،141. } \\
& 27 \text { المرجع السابق، لرجعال142. } \\
& 28 \text { 28 المرجع السابق، ص144. } \\
& 29 \text { المرجع السابق، صلرجعابق ص147. }
\end{aligned}
$$


وحاول الريسوني أن يركز على القاعدة الرابعة، ليخلص منها إلى ضرورة بناء الإطار

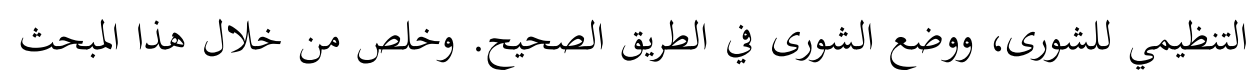

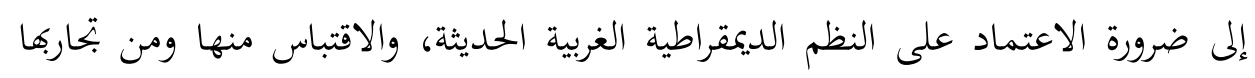

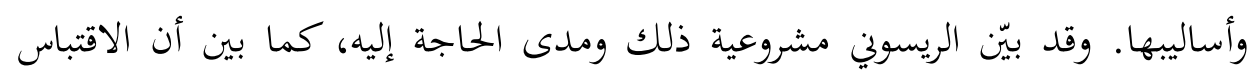

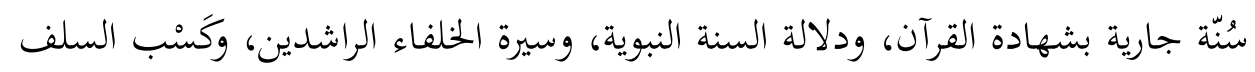
الصالح.

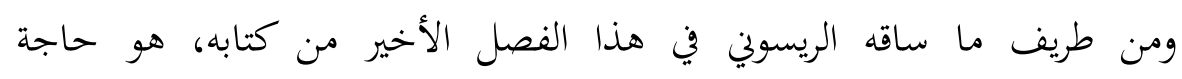

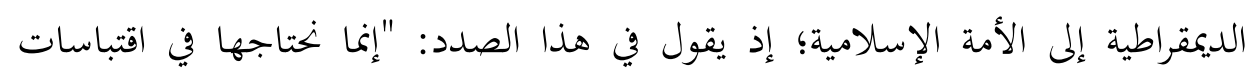

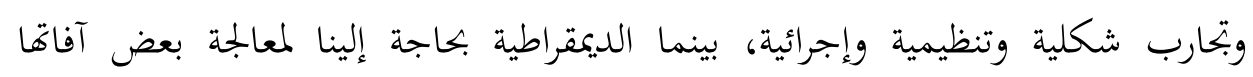

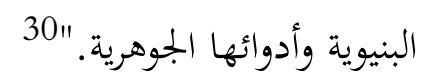

وقد ختم الريسوني بحثه الفريد بتنبيه مهم "ليس بالشورى وحدها!" 31 بيّن فيه

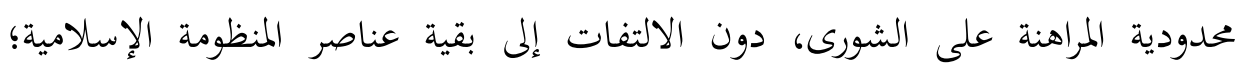

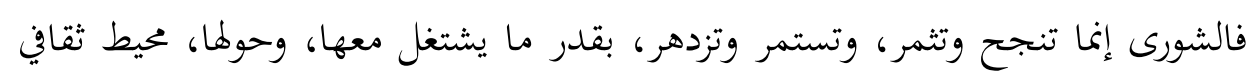

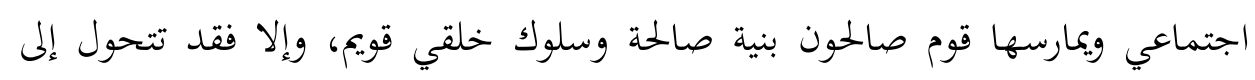

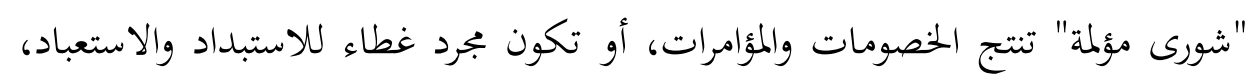

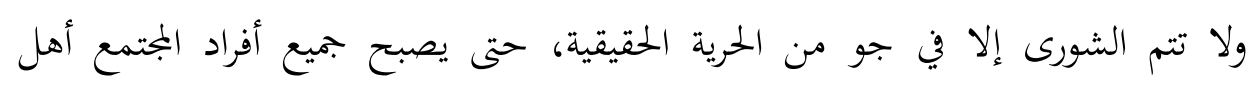
شورى!32

31 32 31 المرجع السابق، ص 162.

